\title{
DBYBHY (2007) ve TBDY (2018) Deprem Yönetmeliklerinin Kesit Hasar Sınırları Açısından Kıyaslanması
}

\author{
Hakan Ulutaş ${ }^{1 *}$ \\ ${ }^{1}$ Burdur Mehmet Akif Ersoy Üniversitesi, Mühendislik Mimarlık Fakültesi, İnşaat Mühendisliği Bölümü, Burdur, Türkiye (ORCID: 0000-0003-1721-7268)
}

(İlk Geliş Tarihi 16 Eylül 2019 ve Kabul Tarihi 22 Ekim 2019)

(DOI: $10.31590 /$ ejosat.620827)

ATIF/REFERENCE: Ulutas, H. (2018). DBYBHY (2007) ve TBDY (2018) Deprem Yönetmeliklerinin Kesit Hasar Sınırları Açısından Kiyaslanması. Avrupa Bilim ve Teknoloji Dergisi, (17), 351-359.

\section{Öz}

Mevcut veya yeni yapılacak betonarme bir yapının deprem güvenliğinin belirlenmesi için öncelikle her bir taşıııı elemanın kesit hasar seviyesinin belirlenmesi gereklidir. Bunun için doğrusal olmayan değerlendirme yöntem ile deprem güvenliği belirlenecek yapı analiz edilir. Yapılan analiz sonucu kesitte oluşan şekil değiştirme değerinin, yürürlükte olan yönetmelikteki kesit hasar seviyesine tekabül eden şekil değiştirme üst sınır değerleri ile kıyaslanması ile kesitin hasar seviyesi elde edilir. Dolayısı ile yapıların deprem güvenliğini belirlenmesinde kesit hasar sınır değerlerinin doğru bir şekilde elde edilmesi oldukça önem arz etmektedir. Bu çalışmada, 2019 yılından önce mevcut yapıların deprem güvenliğinin değerlendirilmesinde kullanılan Deprem Bölgelerinde Yapılacak Yapılar Hakkında Yönetmelik (DBYBHY,2007) ve 2019 yllında yürürlüğe giren Türkiye Bina Deprem Yönetmeliği (TBDY, 2018) kesit hasar sınırları açısından kıyaslanmıştır. Bunun için birer adet kiriş, kolon ve betonarme perde kesiti belirlenmiştir. Yönetmeliklerin kıyaslamasında mevcut yapıları yansıtması amacıyla düşük dayanımlı ve yeni yapılacak yapıları yansıtması amacıyla iyi dayanımlı olmak üzere iki tip malzeme grubu seçilmiştir. Düşük dayanımlı malzeme grubunda; beton sınıfı C10, donatı sınıfı S220, mesnetlerde $250 \mathrm{~mm}$ aralıkta etriye sıklaştırması ve çiroz olmama durumu, iyi dayanımlı malzeme grubunda ise beton sınıfı C25, donatı sınıfı S420, mesnetlerde $10 \mathrm{~mm}$ aralıkta etriye sıklaştırması ve yeterli miktarda çiroz olması durumu seçilmiştir. Ayrıca kolon ve betonarme perde kesitleri için 3 farklı eksenel yük seviyesi belirlenmiş, eksenel yük seviyelerinin her biri her iki farklı malzeme durumunda çözümlenerek toplamda 14 adet kesitin, DBYBHY (2007) ve TBDY (2018) deprem yönetmeliklerine göre kesit hasar seviyesine tekabül eden şekil değiştirme üst sınır değerleri elde edilmiştir. Elde edilen şekil değiş̧irme üst sınır değerlerine bağlı olarak kesit hasar seviyeleri belirlenmiş ve moment eğrilik grafikleri üzerinde gösterilmiştir. Her iki yönetmeliğe göre belirlenen sonuçlar birbiri ile kıyaslanmıştır.

\section{Comparison of TEC (2007) and TBEC (2018) Earthquake Codes in terms of Section Damage Limits}

\begin{abstract}
In order to determine the earthquake safety of an existing or new structure, it is necessary to first determine the cross-sectional damage level of each bearing element. For this purpose, the structure to be determined for earthquake safety is first analyzed with one of the nonlinear assessment methods. The damage level of the section is obtained by comparing the strain value of the cross section with strain upper limit values which is the value corresponding to the level of cross-sectional damage in the code in force. Therefore, it is extremely essantial to obtain accurate cross-sectional damage limit values in determining earthquake safety of buildings. In this
\end{abstract}

\footnotetext{
* *Sorumlu Yazar: Burdur Mehmet Akif Ersoy Üniversitesi, Mühendislik Mimarlık Fakültesi, İnşaat Mühendisliği Bölümü, Burdur, Türkiye, ORCID: 0000-0003-1721-7268, hakannulutas@gmail.com
} 
study, Turkish Building Earthquake Code (TEC, 2007) which was used to evaluate earthquake safety of existing buildings before 2019 and Turkish Building Earthquake Code(TBEC, 2018) which was started to be used since the 2019 were compared in terms of section boundaries damage. For this purpose, one beam, column and shear wall section were determined. Two types of material groups were selected: low quality to reflect existing structures and good quality to reflect new structures for comparison of codes. In low quality material group; concrete grade C10, reinforcement grade S220, structural bearing tie densification at $250 \mathrm{~mm}$ and nondistence piece was selected. In high quality material group; concrete grade C25, reinforcement grade S420, structural bearing tie densification at $10 \mathrm{~mm}$ and the presence of sufficient distence piece was selected. In addition, 3 different axial load levels were determined for column and shear wall sections. Then, the upper limit values of the strains corresponding to the cross-sectional damage level of totally 14 section were obtained based on the TEC (2007) and TBEC (2018) earthquake codes by analysing each of axial load levels. Cross-sectional damage levels were determined depending on the resulting strain upper limit values and were shown on the moment curvature plots. The results determined according to both codes were compared with each other.

Keywords: Section damage limits, Earthquake safety, Moment curvature, Strain

\section{Giriş}

Ülkemiz nüfusunun \%95'i ve büyük sanayi merkezlerinin neredeyse tamamı deprem riski etkisinde olduğundan, bu bölgelerde bulunan binaların depreme güvenli olarak inşaa edilmesi gerekmektedir (Öztürk, 2005, Yaman ve ark., 2019). Ülkemizde meydana gelen büyük depremler neticesinde kentsel bölgelerdeki mevcut binaların deprem riskine karşı oldukça dayanıksız olduğu ortaya çıkmıştır. Dolayısıyla, mevcut betonarme binaların deprem güvenliğinin önceden belirlenmesi ve depreme karşı dayanıksız yapıların güçlendirilmesi hayati önem taşımaktadır (Dilmaç ve ark., 2018). 2019 yılından önce mevcut ve yeni yapılan betonarme yapıların deprem güvenliğinin değerlendirilmesinde Deprem Bölgelerinde Yapılacak Yapılar Hakkında Yönetmelik (DBYBHY,2007) kullanılmaktaydı. 2019 yılından itibaren ise Türkiye Bina Deprem Yönetmeliği (TBDY, 2018) yürürlüğe girmiştir. Yeni deprem yönetmeliğinin yürürlüğe girmesi ile birlikte mevcut ve yeni yapılacak betonarme yapıların deprem güvenliğinin değerlendirmesi konusunda meydana gelen değişikler araştırılmaya başlanmış ve literatürde iki yönetmeliğin birbiri ile kıyaslandığı çalışmalar yayınlanmaya başlamıştır. Elci ve Goker (2018), (DBYBHY (2007) ve TBDY (2018)'i betonarme kolonların deprem performansının değerlendirilmesi açısından karşılaştırılmıştır. Yapılan deneysel ve teorik çalışma sonucu TBDY (2018), DBYBHY (2007)'den daha güvenli tarafta kalan deformasyon limitleri verdiği sonucuna varmışlardır. Nemutlu ve Sarı (2018), 4 ve 9 katlı iki yapıyı TBDY (2018) ve DBYBHY (2007)'de verilen esaslar doğrultunda analiz etmiş, taban kesme kuvvetlerinde meydana gelen değişimlerin nedenlerini gerekçeleriyle birlikte açıklamışlardır. Ulutas ve ark. (2015), FEMA ve Eurocode'da verilen kesit hasar sınırlarını DBYBHY (2007)'de verilen hasar sınırlarıyla kıyaslamışlardır. Işıltan (2010), Betonarme kolonlar için DBYBHY (2007), Eurocode 8 ve FEMA 356 ile yapılan performans değerlendirmelerini yaptığı deney sonuçlarıyla karşılaştırılmasını yapmıştır.

Performans esaslı değerlendirme yönteminin en önemli aşamalarından birisi yapısal elemanların her birinin hasar düzeylerinin belirlenmesidir. Doğrusal olmayan değerlendirme yöntemi ile analiz edilen yapıdaki yapısal elemanların kesitlerinde oluşan şekil değiştirme değerinin, yürürlükte olan yönetmelikteki kesit hasar seviyesine tekabül eden şekil değiştirme üst sınır değerleri ile kıyaslanması ile kesitin hasar seviyesi elde edilir. Dolayısı ile yapıların deprem güvenliğini belirlemede kesit hasar sınır değerlerinin doğru bir şekilde elde edilmesi oldukça önem arz etmektedir. Eleman davranışı kesit davranışından ve kesitin moment-eğrilik ilişkisinden izlenilebilir (Ersoy vd., 1998).

Bu çalışmada, TBDY (2018) ve DBYBHY (2007) kesit hasar sınırları açısından kıyaslanmıştır. Bunun için birer adet kiriş, kolon ve betonarme perde kesiti belirlenmiştir. Yönetmeliklerin kıyaslamasında mevcut yapıları yansıtması amacıyla düşük dayanımlı ve yeni yapılacak yapıları yansıtması amacıyla iyi dayanımlı olmak üzere iki tip malzeme grubu seçilmiştir. Düşük dayanımlı malzeme grubunda; beton sınıfi C10, donatı sınıfı S220, mesnetlerde $250 \mathrm{~mm}$ aralıkta etriye sıklaştırması ve çiroz olmama durumu, iyi dayanımlı malzeme grubunda ise beton sınıfı C25, donatı sınıfı S420, mesnetlerde $10 \mathrm{~mm}$ aralıkta etriye sıklaştırması ve yeterli miktarda çiroz olması durumu seçilmiştir. Kiriş kesiti için eksenel yük seviyesi sıfır alınmış, kolon ve betonarme perde kesitleri için 3 farklı eksenel yük seviyesi belirlenmiştir. Eksenel yük seviyelerinin her biri her iki farklı malzeme durumunda çözümlenerek toplamda 14 adet kesitin, DBYBHY (2007) ve TBDY (2018) deprem yönetmeliklerine göre kesit hasar seviyesine tekabül eden şekil değiştirme üst sınır değerleri elde edilmiştir. Elde edilen şekil değiştirme üst sınır değerlerine bağlı olarak kesit hasar seviyeleri belirlenmiş ve moment eğrilik grafikleri üzerinde gösterilmiştir. Her iki yönetmeliğe göre belirlenen sonuçlar birbiri ile kıyaslanmıştır.

\section{Materyal ve Metot}

\subsection{Betonarme Kesitlerin Hasar Sinırları ve Hasar Bölgeleri}

\subsubsection{DBYBHY(2007)'e göre Betonarme Kesitlerin Hasar Sınırlart ve Hasar Bölgelerinin Belirlemesi}

DBYBHY (2007)'de sünek elemanlar için Minimum Hasar Sınırı (MN), Güvenlik Sınırı (GV) ve Göçme Sınırı (GÇ) olmak üzere kesit düzeyinde üç sınır durum tanımlanmıştır. Minimum hasar sınırı ilgili kesitte elastik ötesi davranışın başlangıcını, güvenlik sınırı kesitin dayanımını güvenli olarak sağlayabileceği elastik ötesi davranışın sınırını, göçme sınırı ise kesitin göçme öncesi davranışının sınırını tanımlamaktadır. Gevrek olarak hasar gören elemanlarda bu sınıflandırma geçerli olmamaktadır.

Binanın tepe yerdeğiştirme istemine kadar yatay yükün artırılması ile betonarme kesitlerde meydana gelen iç kuvvetlerin ve/veya şekildeğiştirmelerin Tablo 1'de tanımlanan birim şekildeğiştirme sınırları ile karşılaştırılması sonucunda, kesitlerin hasar düzeylerine karar verilir. Elemanın en fazla hasar gören kesiti eleman hasarı olarak tanımlanır. 
Kritik kesitlerinin hasarı MN'yi geçmeyen elemanlar Minimum Hasar Bölgesi'nde, MN ile GV arasında kalan elemanlar Belirgin Hasar Bölgesi'nde, GV ve GÇ arasında kalan elemanlar İleri Hasar Bölgesi'nde, GÇ'yi aşan elemanlar ise Göçme Bölgesi'nde yer alırlar (Şekil 1).

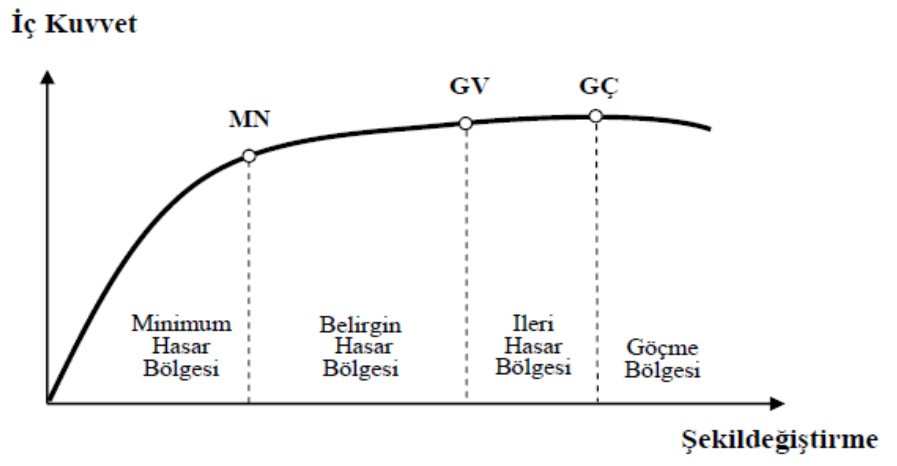

Şekil 1. Kesit hasar sinırlart ve hasar bölgeleri (DBYBHY, 2007).

Tablo 1. Çeşitli kesit hasar sınırlarına göre izin verilen şekildeğiştirme üst sınırları (DBYBHY, 2007)

\begin{tabular}{|l|l|l|}
\hline Kesit hasar sınırı & Beton şekildeğiştirme üst sınırları & $\begin{array}{l}\text { Donatı çeliği } \\
\text { şekildeğiştirme üst } \\
\text { snırları }\end{array}$ \\
\hline $\begin{array}{l}\text { Minimum Hasar } \\
\text { Sınırı }\end{array}$ & $\left(\varepsilon_{\mathrm{cu}}\right)=0.0035$ & $\left(\varepsilon_{\mathrm{s}}\right)=0.010$ \\
\hline Güvenlik Sınırı & $\left(\varepsilon_{\mathrm{cg}}\right)=0.0035+0.01\left(\rho_{\mathrm{s}} / \rho_{\mathrm{sm}}\right) \leq 0.0135$ & $\left(\varepsilon_{\mathrm{s}}\right)=0.040$ \\
\hline Göçme Sınırı & $\left(\varepsilon_{\mathrm{cg}}\right)=0.004+0.014\left(\rho_{\mathrm{s}} / \rho_{\mathrm{sm}}\right) \leq 0.018$ & $\left(\varepsilon_{\mathrm{s}}\right)=0.060$ \\
\hline
\end{tabular}

Burada, $\varepsilon_{\mathrm{cu}}$, kesitin en dış lifindeki beton basınç birim şekildeğiştirmesini; $\varepsilon_{\mathrm{cg}}$, etriye içindeki bölgenin en dış lifindeki beton basınç birim şekildeğiştirmesini; $\varepsilon_{s}$, donatı çeliği birim şekildeğiştirmesini; $\rho_{\mathrm{s}}$, kesitte mevcut bulunan ve DBYBHY (2007) Bölüm 3.2.8'e göre "özel deprem etriyeleri ve çirozları" olarak düzenlenmiş enine donatının hacimsel oranını; $\rho_{\text {sm, }}$ DBYBHY (2007) Bölüm 3.3.4, 3.4.4 veya 3.6.5.2'ye göre tanımlanan kesitte bulunması gereken enine donatının hacimsel oranını ifade etmektedir.

\subsubsection{TBDY(2018)'e göre Betonarme Kesitlerin Hasar Sınırlart ve Hasar Bölgelerinin Belirlemesi}

TBDY(2018)'de Sünek elemanlar için kesit düzeyinde üç hasar durumu ve hasar sınırı tanımlanmıştır. Bunlar Sinırlı Hasar (SH), Kontrollü Hasar (KH) ve Göçme Öncesi Hasar (GÖ) durumları ve bunların sınır değerleridir. Sınırlı hasar ilgili kesitte sınırlı miktarda elastik ötesi davranışı, kontrollü hasar kesit dayanımının güvenli olarak sağlanabileceği elastik ötesi davranışı, göçme öncesi hasar durumu ise kesitte ileri düzeyde elastik ötesi davranışı tanımlamaktadır. Gevrek olarakhasar gören elemanlarda bu sınıflandırma geçerli değildir (TBDY,2018).

Binanın tepe yerdeğiştirme istemine kadar yatay yükün artırılması ile betonarme kesitlerde meydana gelen iç kuvvetlerin ve/veya şekildeğiştirmelerin Tablo 2'de tanımlanan birim şekildeğiştirme sınırları ile karşılaştırılması sonucunda, kesitlerin hangi hasar bölgelerinde olduğuna karar verilir. Elemanın en fazla hasar gören kesiti eleman hasarı olarak tanımlanır.

Kritik kesitlerinin hasarı SH'ya ulaşmayan elemanlar Stnırlı Hasar Bölgesi'nde, SH ile KH arasında kalan elemanlar Belirgin Hasar Bölgesi'nde, KH ile GÖ arasında kalan elemanlar Illeri Hasar Bölgesi'nde, GÖ'yü aşan elemanlar ise Göçme Bölgesi'nde yer alırlar (Şekil 2).

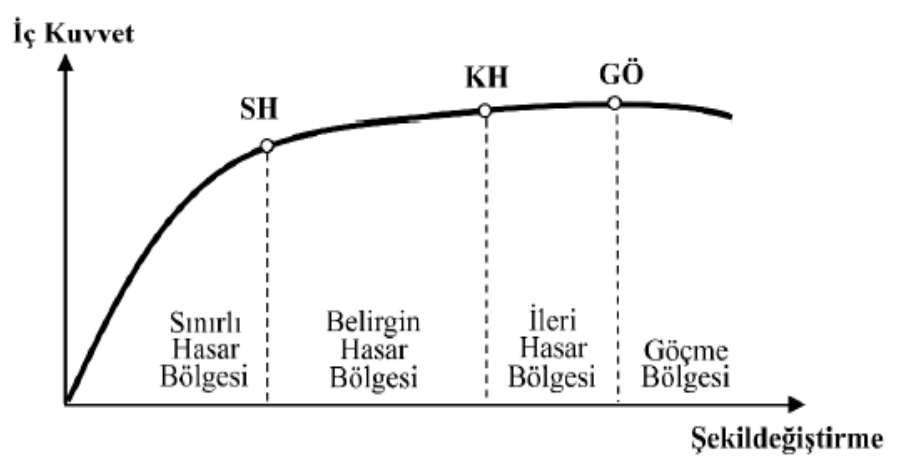

Şekil 2. Kesit hasar sinırları ve hasar bölgeleri (TBDY,2018)

Tablo 2. Çeşitli kesit hasar sınırlarına göre izin verilen şekildeğiştirme üst sınırları (TBDY, 2018) 


\begin{tabular}{|l|c|l|}
\hline & & $\begin{array}{l}\text { şekildeğiştirme üst } \\
\text { sınırları }\end{array}$ \\
\hline Sınırlı Hasar & $\varepsilon_{c}^{(S H)}=0.0025 ;$ & $\varepsilon_{s}^{(S H)}=0.0075$ \\
\hline Kontollu Hasar & $\varepsilon_{c}^{(K H)}=0.75 \varepsilon_{c}^{(G \ddot{O})}$ & $\varepsilon_{s}^{(K H)}=0.75 \varepsilon_{s}^{(G \ddot{O})}$ \\
\hline $\begin{array}{l}\text { Göçmenin } \\
\text { önlenmesi }\end{array}$ & $\varepsilon_{c}^{(G \ddot{O})}=0.0035+0.04 \sqrt{\omega_{w e}} \leq 0.018$ & $\varepsilon_{c}^{(G \ddot{O})}=0.4 \varepsilon_{s u}$ \\
\hline
\end{tabular}

Burada; $\omega_{\text {we }}$ etkin sargı donatısının mekanik donatı oranı'nı göstermekte olup Denklem 1 ile elde edilir.

$\omega_{w e}=\alpha_{s e} \rho_{s h, \min } \frac{f_{y w e}}{f_{c e}}$

Denklem 1'de yer alan $\alpha_{\text {se }}$ Sargl donatısı etkinlik katsayısı'nı, $\rho_{\text {sh,min }}$ dikdörtgen kesitte iki yatay doğrultuda hacimsel enine donatı oranının küçük olanını, $f_{\text {ywe }}$ enine donatının ortalama (beklenen) akma dayanımı olup donatı sınıfına bağlı olarak Tablo 3 'te verilmiştir.

Tablo 3. Ortalama(beklenen) malzeme dayanımları (TBDY,2018)

\begin{tabular}{|c|c|}
\hline Beton & $f_{c e}=1.3 f_{c k}$ \\
\hline Donatı çeliği & $f_{y e}=1.2 f_{y k}$ \\
\hline Yapı çeliği (S235) & $f_{y e}=1.5 f_{y k}$ \\
\hline Yapı çeliği (S275) & $f_{y e}=1.3 f_{y k}$ \\
\hline Yap çeliği (S355) & $f_{y e}=1.1 f_{y k}$ \\
\hline Yapı çeliği (S460) & $f_{y e}=1.1 f_{y k}$ \\
\hline
\end{tabular}

$\alpha_{\mathrm{se}}=\left(\frac{\sum \mathrm{a}_{\mathrm{i}}^{2}}{6 \mathrm{~b}_{\mathrm{o}} \mathrm{h}_{\mathrm{o}}}\right)\left(1-\frac{\mathrm{s}}{2 \mathrm{~b}_{\mathrm{o}}}\right)\left(1-\frac{\mathrm{s}}{2 \mathrm{~h}_{\mathrm{o}}}\right) ; \rho_{s h}=\frac{A_{s h}}{b_{k} s}$

Denklem 2'de $A_{\text {sh }}$ ve $\rho_{\text {sh }}$ göz önüne alınan doğrultuda enine donatının alanını ve hacimsel oranını, $b_{\mathrm{k}}$ dik doğrultudaki çekirdek boyutunu (en dıştaki enine donatı eksenleri arasındaki uzaklık), $s$ enine donatı aralığını, $b_{0}$ ve $h_{0}$ sargı donatısı eksenlerinden ölçülen sargılı beton boyutlarını, $a_{\mathrm{i}}$ bir etriye kolu veya çiroz tarafindan mesnetlenen boyuna donatıların eksenler arasındaki uzaklığı göstermektedir.

Burada $\varepsilon_{\text {su }}$ ise çekme dayanımına karşı gelen birim uzamayı göstermekte olup donatı sınıfına bağlı olarak değerler Tablo 4'de verilmiş̧ir.

Tablo 4. Donatı çeliklerine ait bilgiler (TBDY,2018)

\begin{tabular}{|c|c|c|c|c|c|}
\hline Kalite & $f_{s y(M p a)}$ & $\varepsilon_{s y}$ & $\varepsilon_{s h}$ & $\varepsilon_{s u}$ & $f_{s u} / f_{s y}$ \\
\hline S220 & 220 & 0.0011 & 0.011 & 0.12 & 1.2 \\
\hline S420 & 420 & 0.0021 & 0.008 & 0.008 & $1.15-1.35$ \\
\hline B420C & 420 & 0.0021 & 0.008 & 0.008 & $1.15-1.35$ \\
\hline B500C & 500 & 0.0025 & 0.008 & 0.008 & $1.15-1.35$ \\
\hline
\end{tabular}

\subsection{Kesit ve Malzemenin Belirlenmesi}

Çalışma kapsamında DBYBHY(2007) ve TBDY(2018) yönetmeliklerini kesit hasar sınırları açısından kıyaslamak için birer adet kiriş, kolon ve betonarme perde kesiti seçilmiştir. Yönetmeliklerin kıyaslamasında mevcut betonarme binaların taşıyıcı sistem elemanlarını yansıtması amacıyla düşük dayanımlı ve yeni yapılacak yapıları yansıtması amacıyla iyi dayanımlı olmak üzere iki tip malzeme grubu seçilmiştir. Düşük dayanımlı malzeme grubunda; beton sınıfı C10, donatı sınıfı S220, mesnetlerde $250 \mathrm{~mm}$ aralıkta etriye sıklaştırması ve çiroz olmama durumu, iyi dayanımlı malzeme grubunda ise beton sınıf C25, donatı sınıfı S420, mesnetlerde 10 mm aralıkta etriye sıklaştırması ve yeterli miktarda çiroz olması durumu seçilmiştir. Kolon kesitlerinin donatı oranı; DBYBHY (2007) ve TBDY (2018)'de verilen minimum donatı oranı olan \%1 olarak seçilmiştir. Betonarme perdeler donatı oranı ise yine DBYBHY (2007) ve TBDY (2018)'de verilen minimum donatı oranı kullanılarak seçilmiştir. Bunun için uç kısımların her birinde \%0.2, gövdeye $\% 0.25$ oranında donatı yerleştirilmiştir. Düşük ve iyi dayanımlı malzeme grupları için belirlenen betonarme kesitler Şekil 3 'te verilmiştir. 


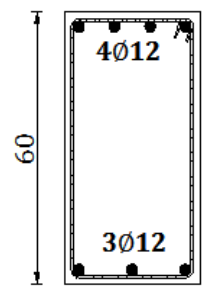

30

Kiriş kesiti

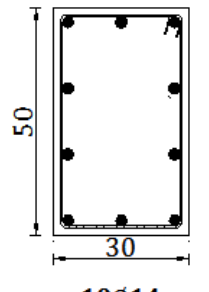

$10 \emptyset 14$

Kolon kesiti

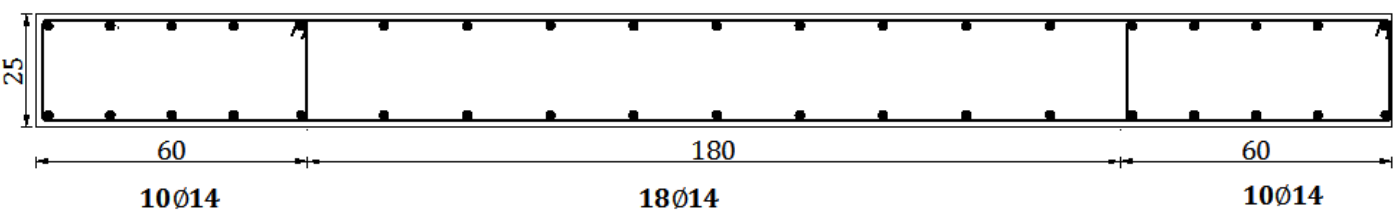

Betonarme perde kesiti

Şekil 3.a. Düşük dayanımlı malzeme durumu için kullanılan kesitler

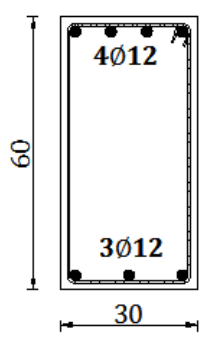

Kiriș kesiti

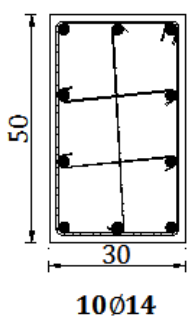

Kolon kesiti

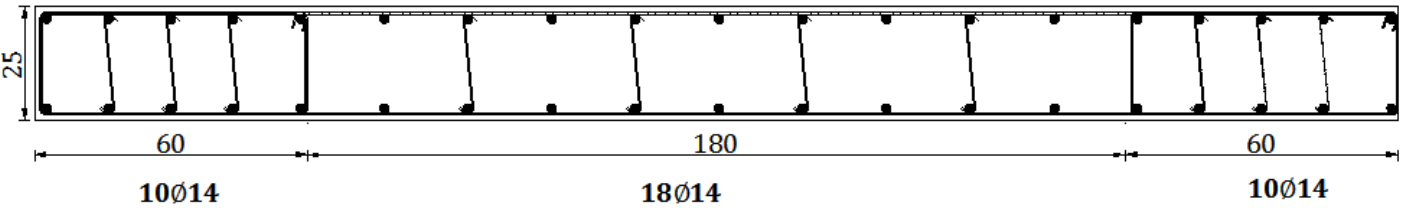

Betonarme perde kesiti

Şekil 3.b. Iyi dayanımlı malzeme durumu için kullanılan kesitler

\subsection{Kesit Hasar Sınırlarının Elde Edilmesi}

Çalışma kapsamında, Tablo 1 ve Tablo 2'de tanımlanan sınırlar kullanılarak her bir kesitin iki farklı malzeme durumu için birim şekildeğiştirme üst sınırları hesaplanmıştır. Elde edilen değerler Tablo 5'de verilmiştir.

Tablo 5.a. Kiriş kesitinin beton ve donatı için elde edilen şekildeğiştirme üst sınırları

\begin{tabular}{|c|c|c|c|c|c|}
\hline \multirow[b]{2}{*}{ Yönetmelik } & \multirow[b]{2}{*}{ Kesit hasar sınırı } & \multicolumn{2}{|c|}{ Düsük dayanımlı malzeme } & \multicolumn{2}{|c|}{ İyi dayanımlı malzeme } \\
\hline & & $\begin{array}{l}\text { Beton } \\
\text { şekildeğiştirme } \\
\text { üst sınırları }\end{array}$ & $\begin{array}{l}\text { Donatı çeliği } \\
\text { Şekildeğiştirme } \\
\text { üst sınırları }\end{array}$ & $\begin{array}{l}\text { Beton } \\
\text { şekildeğiştirme } \\
\text { üst sınırları }\end{array}$ & $\begin{array}{l}\text { Donatı çeliği } \\
\text { Şekildeğiştirme } \\
\text { üst sınırları }\end{array}$ \\
\hline \multirow{3}{*}{ DBYBHY(2007) } & $\mathrm{MN}$ & 0.0035 & 0.01 & 0.0035 & 0.01 \\
\hline & GV & 0.0075 & 0.04 & 0.0135 & 0.04 \\
\hline & GÇ & 0.0096 & 0.06 & 0.018 & 0.06 \\
\hline \multirow{3}{*}{ TBDY(2018) } & $\mathrm{SH}$ & 0.0025 & 0.0075 & 0.0025 & 0.0075 \\
\hline & $\mathrm{KH}$ & 0.0037 & 0.0360 & 0.0045 & 0.0240 \\
\hline & GÖ & 0.0049 & 0.0480 & 0.0061 & 0.0320 \\
\hline
\end{tabular}

Tablo5.b. Kolon kesitinin beton ve donatı için elde edilen şekildeğiştirme üst sınırları

\begin{tabular}{|c|c|c|c|c|c|}
\hline \multirow[b]{2}{*}{ Yönetmelik } & \multirow[b]{2}{*}{ Kesit hasar sınırı } & \multicolumn{2}{|c|}{ Düşük dayanımlı malzeme } & \multicolumn{2}{|c|}{ İyi dayanımlı malzeme } \\
\hline & & $\begin{array}{l}\text { Beton } \\
\text { şekildeğiştirme } \\
\text { üst sınırları }\end{array}$ & $\begin{array}{l}\text { Donatı çeliği } \\
\text { Şekildeğiştirme } \\
\text { üst sınırları }\end{array}$ & $\begin{array}{l}\text { Beton } \\
\text { şekildeğiştirme } \\
\text { üst sınırları }\end{array}$ & $\begin{array}{l}\text { Donatı çeliği } \\
\text { Şekildeğiştirme } \\
\text { üst sınırları }\end{array}$ \\
\hline \multirow{3}{*}{ DBYBHY(2007) } & $\mathrm{MN}$ & 0.0035 & 0.01 & 0.0035 & 0.01 \\
\hline & GV & 0.0059 & 0.04 & 0.0135 & 0.04 \\
\hline & GÇ & 0.0073 & 0.06 & 0.0180 & 0.06 \\
\hline \multirow{3}{*}{ TBDY(2018) } & $\mathrm{SH}$ & 0.0025 & 0.0075 & 0.0025 & 0.0075 \\
\hline & $\mathrm{KH}$ & 0.0040 & 0.0360 & 0.0083 & 0.0240 \\
\hline & GÖ & 0.0053 & 0.0480 & 0.0111 & 0.0320 \\
\hline
\end{tabular}


Tablo5.c. Betonarme perde kesitinin beton ve donatı için elde edilen şekildeğiştirme üst slnırları

\begin{tabular}{|c|c|c|c|c|c|}
\hline \multirow[b]{2}{*}{ Yönetmelik } & \multirow[b]{2}{*}{ Kesit hasar sinırı } & \multicolumn{2}{|c|}{ Düşük dayanımlı malzeme } & \multicolumn{2}{|c|}{ İyi dayanımlı malzeme } \\
\hline & & $\begin{array}{l}\text { Beton } \\
\text { şekildeğiştirme } \\
\text { üst sınırları }\end{array}$ & $\begin{array}{l}\text { Donatı çeliği } \\
\text { Şekildeğiştirme } \\
\text { üst sınırları }\end{array}$ & $\begin{array}{l}\text { Beton } \\
\text { şekildeğiştirme } \\
\text { üst sınırları }\end{array}$ & $\begin{array}{l}\text { Donatı çeliği } \\
\text { Şekildeğiştirme } \\
\text { üst sınırları }\end{array}$ \\
\hline \multirow{3}{*}{ DBYBHY(2007) } & MN & 0.0035 & 0.01 & 0.0035 & 0.01 \\
\hline & GV & 0.0068 & 0.04 & 0.0135 & 0.04 \\
\hline & GÇ & 0.0086 & 0.06 & 0.0180 & 0.06 \\
\hline \multirow{3}{*}{ TBDY(2018) } & $\mathrm{SH}$ & 0.0025 & 0.0075 & 0.0025 & 0.0075 \\
\hline & $\mathrm{KH}$ & 0.0026 & 0.0360 & 0.0066 & 0.0240 \\
\hline & GÖ & 0.0035 & 0.0480 & 0.0088 & 0.0320 \\
\hline
\end{tabular}

Kesitlerin her iki malzeme durumu için beton ve donatı şekildeğiştirme üst sınırları belirlendikten sonra kesit hasar sınırları belirlenmiştir. Bunun için kesitin en dış lifindeki beton basınç birim şekildeğiştirmesi 0.0001 değerinden başlanmış ve kuvvet dengesinden yararlanarak bu birim şekil değiştirme anındaki donatı şekil değiştirmeleri hesaplanmıştır. Beton ve donatıdan şekildeğiştirme üst sınır değerine önce ulaşan kesitin hasarını ve eğrilik değerini belirlemiştir. Tüm bu işlemler için Excel'de bir program yazılmıştır. Programda Mander sargılı ve sargısız gerilme şekil değiştirme diyagramları kullanılmıştır. Kullanılan kiriş, kolon ve betonarme perde kesitlerinin Mander gerilme şekil değiştirme grafikleri Şekil 4'de verilmiştir..

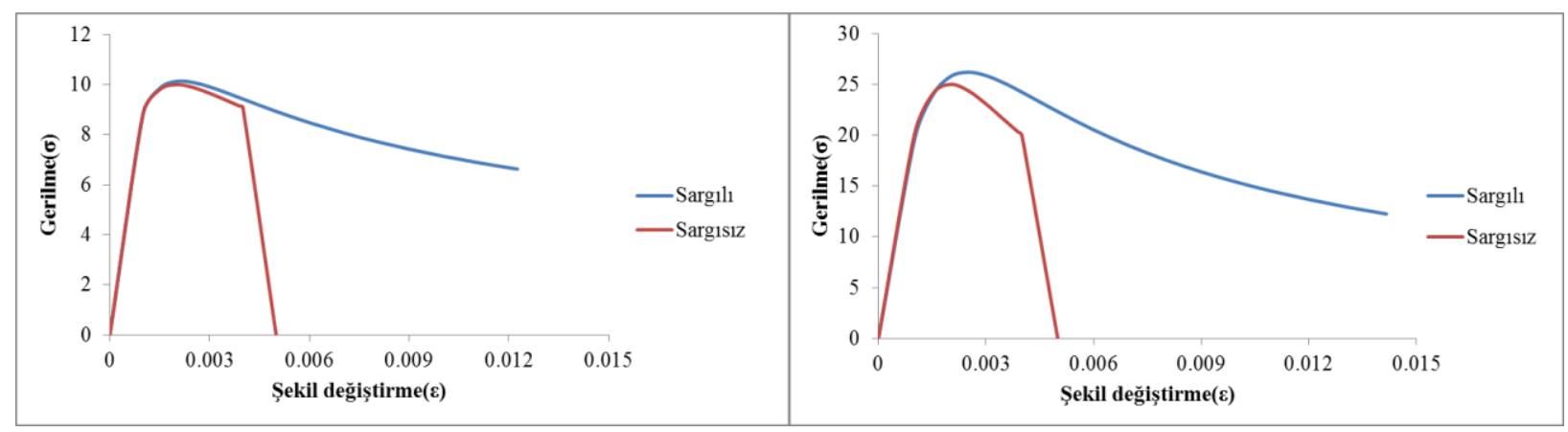

(a) Düşük dayanımlı kiriş kesiti

(b) İyi dayanımlı kiriş kesiti

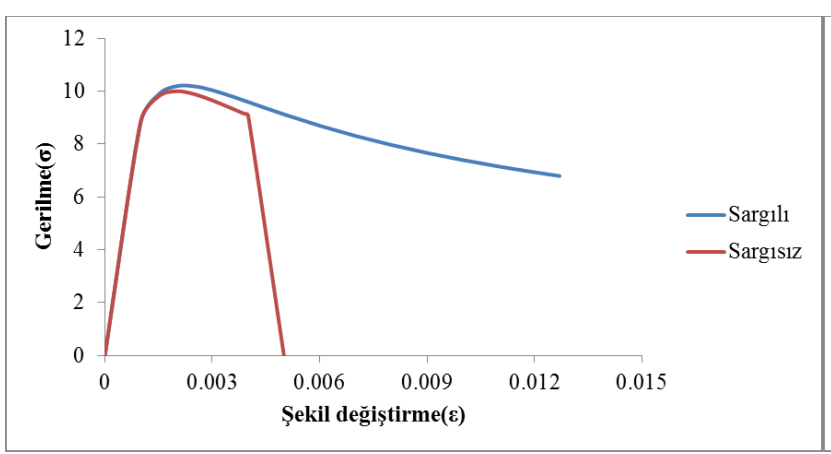

(c) Düşük dayanımlı kolon kesiti

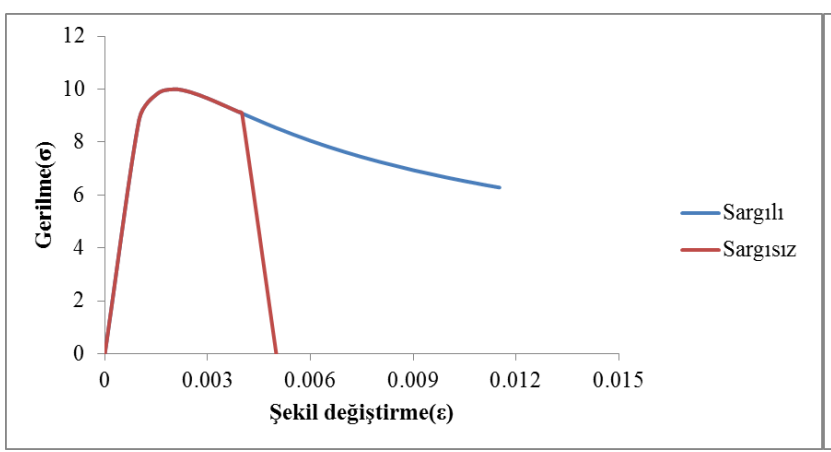

(e) Düşük dayanımlı betonarme perde kesiti

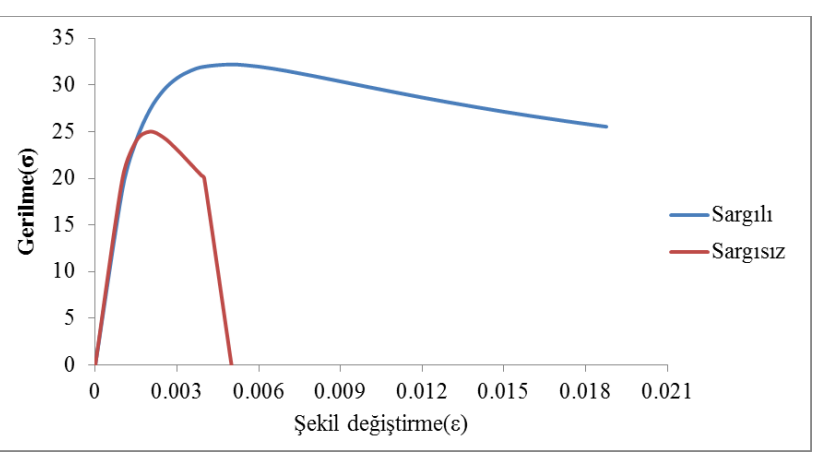

(d) İyi dayanımlı kolon kesiti

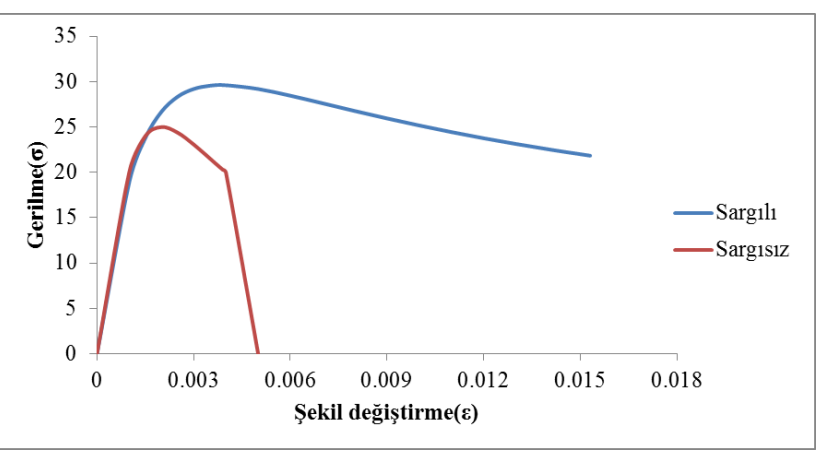

(f) İyi dayanımlı betonarme perde kesiti

\section{Şekil 4. Kesitlerin Mander gerilme şekil değiştirme grafikleri}

Düşük dayanımlı kesitlere bakıldığında (Şekil 4.a- Şekil 4.c-şekil 4.e), etriye aralığının çok seyrek olması ve çiroz kullanılmamış olması sargılı ve sargısız Mander gerilme şekil değiştirme grafiklerinin maksimum gerilme değerlerinin aynı olmasına sebep olduğu görülmektedir. 
DBYBHY (2007) ve TBDY (2018) deprem yönetmeliklerine göre belirlenen hasar sınırları iç kuvvet-şekil değiştirme grafiği üzerinde gösterilmiş ve iki yönetmelik daha belirgin bir şekilde kıyaslanabilmiştir. Kirişlerin moment eğrilik grafikleri eksenel yük seviyesi sıfır alınarak elde edilmiştir. Kolon ve betonarme perde kesitlerinde ise kesite ait eksenel yük/kesitin eksenel yük taşıma kapasitesi $\left(\mathrm{N} / \mathrm{N}_{\text {or }}\right)$ oranı; 0.25, 0.5, 0.75 olmak üzere 3 farklı eksenel yük seviyesi için moment eğrilik grafikleri elde edilmiştir. Eksenel yük seviyelerinin her biri her iki farklı malzeme durumu için çözümlendiğinden toplamda 14 adet moment eğrilik grafiği elde edilmiştir. Kiriş, kolon ve betonarme perde kesitlerinin her iki malzeme durumu için elde edilen kesit hasar sınırlarınin moment eğrilik grafikleri üzerinde gösterimi (Şekil 5-Şekil 9)'de verilmiştir. Grafiklerde, iki yönetmelikte birbirine tekabül eden sınırlar aynı renk ile gösterilmiştir. Koyu dikdörtgen çerçeveli sınırlar DBYBHY (2007)’e göre elde edilen sınırlardır.

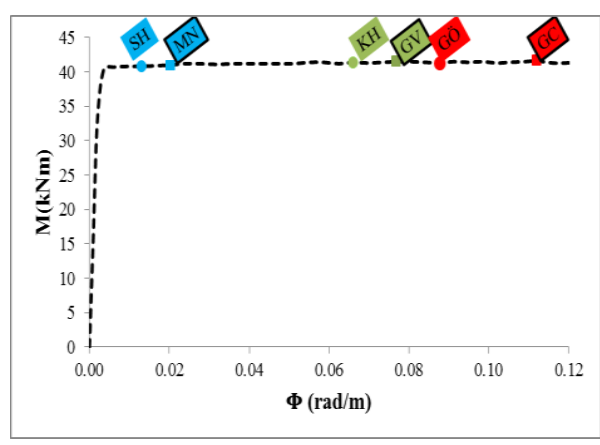

(a)

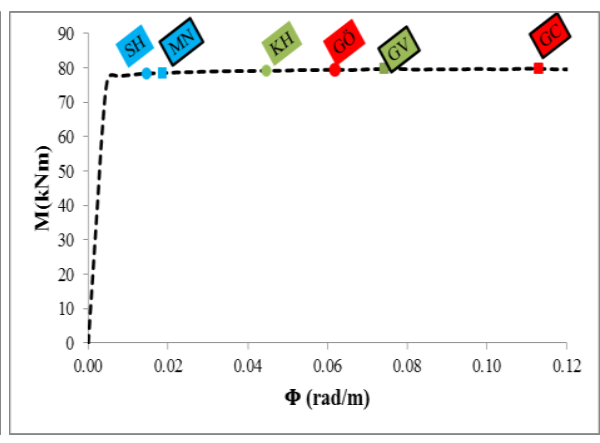

(b)

Şekil 5. Kiriş kesitinin düşük(a) ve iyi(b) dayanımlı malzeme durumları için moment ĕgrilik grafikleri ve kesit hasar sınırları

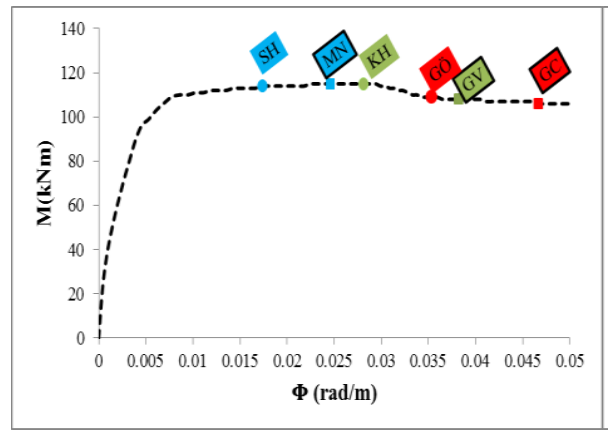

(a)

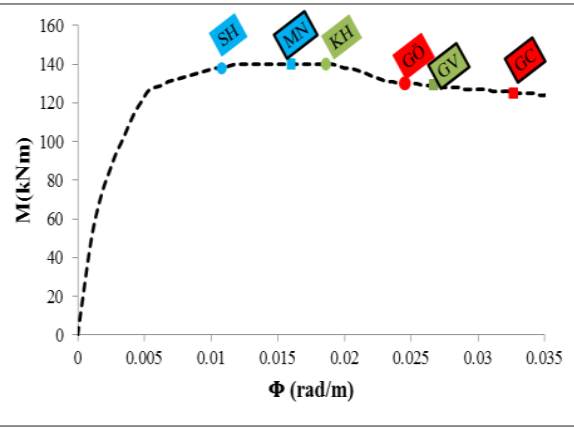

(b)

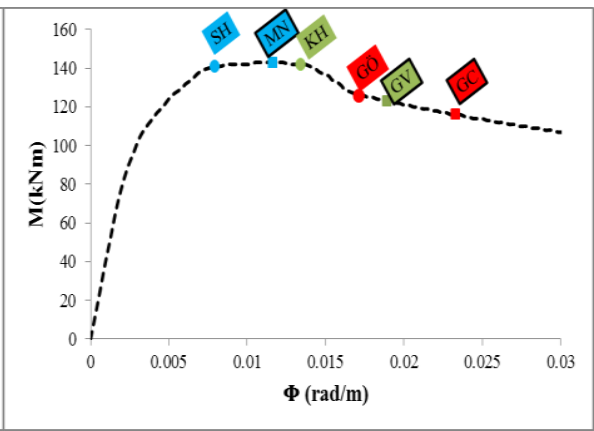

(c)

Şekil 6. Düşük dayanımlı kolon kesitinin $N / N_{\text {or: }}: 0.25(a)$, N/Nor:0.5(b), $N / N_{\text {or: }}: 0.75(c)$ durumları için moment eğrilik grafikleri ve kesit hasar sinırlart

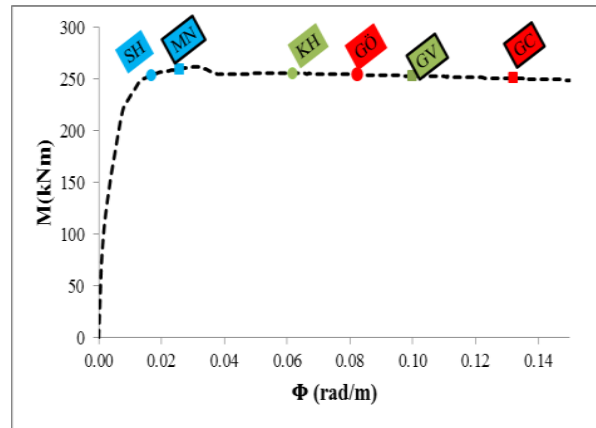

(a)

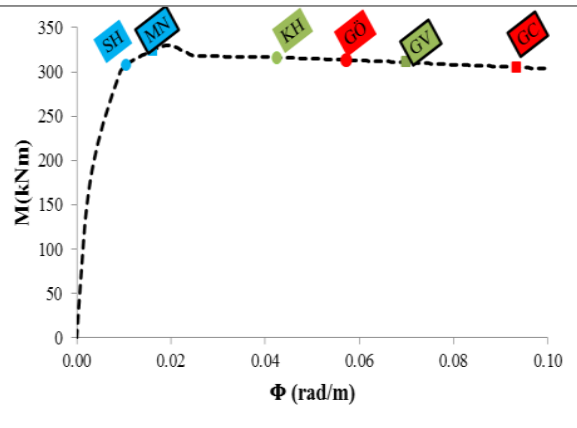

(b)

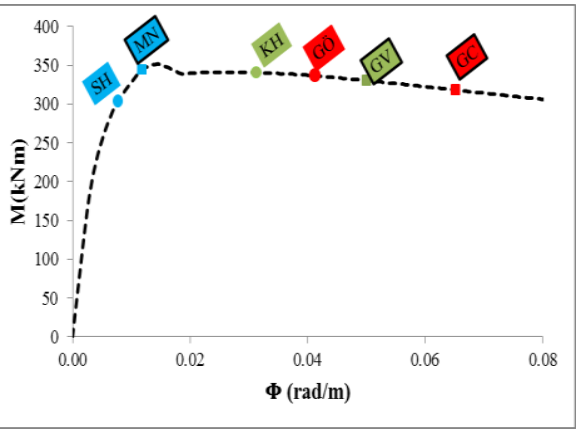

(c)

Şekil 7. Iyi dayanımlı kolon kesitinin $N / N_{\text {or }}: 0.25(a), N / N_{o r}: 0.5(b), N / N_{o r}: 0.75(c)$ durumlart için moment eğrilik grafikleri ve kesit hasar sinırlart 


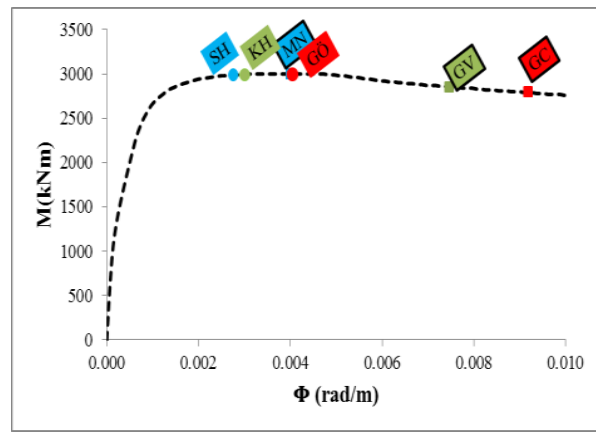

(a)

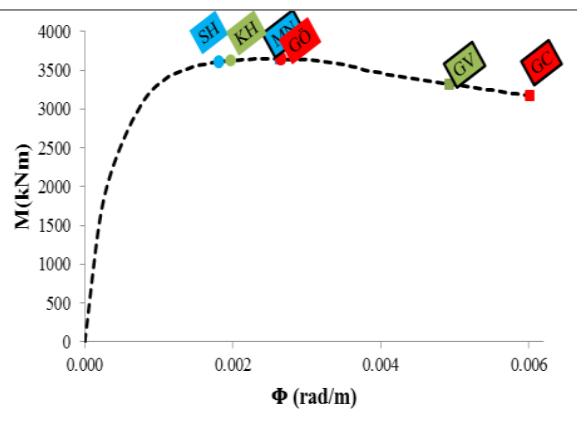

(b)

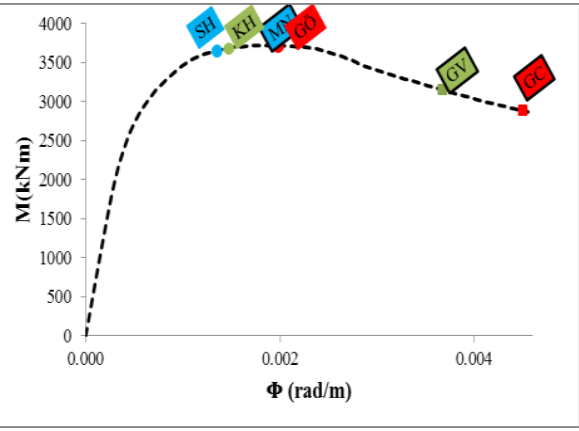

(c)

Şekil 8. Düşük dayanımlı betonarme perde kesitinin $N / N_{\text {or }}: 0.25(a), N / N_{\text {or }}: 0.5(b), N / N_{\text {or }}: 0.75(c)$ durumlarl için moment eğrilik grafikleri ve kesit hasar sinırlarl

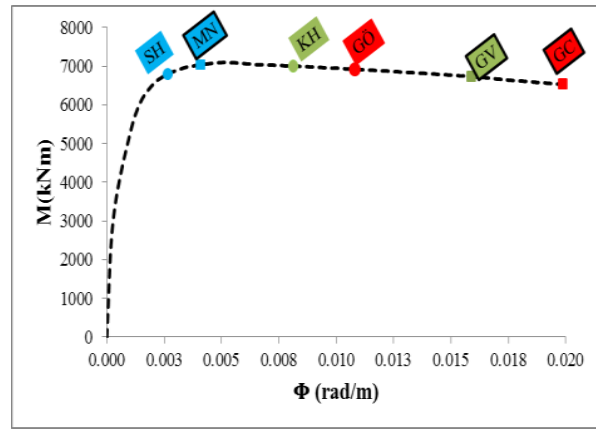

(a)

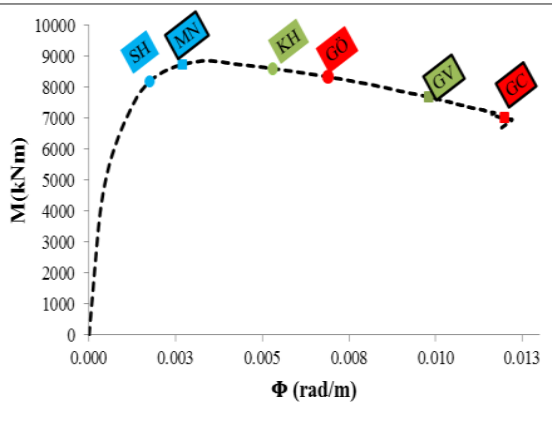

(b)

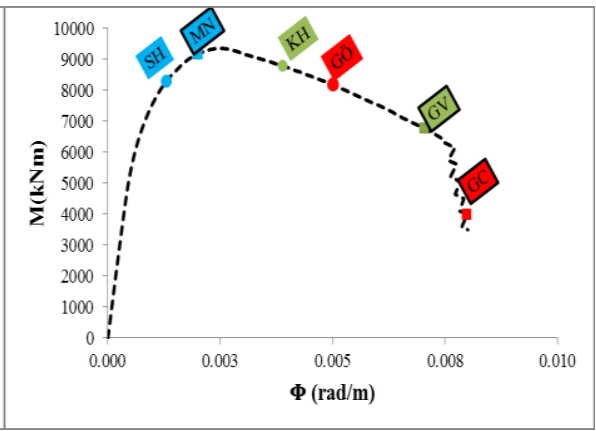

(c)

Şekil 9. Iyi dayanımlı betonarme perde kesitinin $N / N_{\text {or }}: 0.25(a), N / N_{o r}: 0.5(b), N / N_{o r}: 0.75(c)$ durumlarl için moment eğrilik grafikleri ve kesit hasar sinırlart

\section{Araştırma Sonuçları ve Tartışma}

Bu çalışmada, Deprem Bölgelerinde Yapılacak Yapılar Hakkında Yönetmelik (DBYBHY,2007) ve Türkiye Bina Deprem Yönetmeliği (TBDY, 2018) kesit hasar sınırları açısından kıyaslanmıştır. Bunun için birer adet kiriş, kolon ve betonarme perde kesiti ile düşük ve iyi dayanımlı olmak üzere iki malzeme grubu seçilmiştir. Kiriş kesitinin eksenel yük seviyesi sıfır alınmış, kolon ve betonarme perde kesitleri için 3 farklı eksenel yük seviyesi belirlenmiştir. Eksenel yük seviyelerinin her biri her iki farklı malzeme durumunda çözümlenerek toplamda 14 adet kesitin, DBYBHY (2007) ve TBDY (2018) deprem yönetmeliklerine göre kesit hasar seviyesine tekabül eden şekil değiştirme üst sınır değerleri elde edilmiştir. Elde edilen şekil değiştirme üst sınır değerlerine bağlı olarak kesit hasar seviyeleri hazırlanan bir excel yazılımı ile belirlenmiş ve moment eğrilik grafikleri üzerinde gösterilmiştir. Her iki yönetmeliğe göre belirlenen sonuçlar birbiri ile kıyaslanmıştır. Elde edilen sonuçlar doğrultusunda;

1) DBYBHY (2007)'de donatı çeliği şekildeğiştirme üst sınırları donatı sınıfından bağımsız iken TBDY (2018)'de donatinin maksimum uzama şekildeğiştime değerine $\left(\varepsilon_{\mathrm{su}}\right)$ bağlı olarak donatı çeliği şekildeğiştirme üst sınırları değişmektedir.

2) Mevcut yapılardaki malzeme durumunu yansıtması amacıyla belirlenen düşük dayanımlı malzemede yeterli miktarda enine donatı bulunmadığından $\rho_{\mathrm{s}} / \rho_{\mathrm{sm}}$ değeri düşük oranda olmakta dolayısı ile beton şekildeğiştirme üst sınırları de düşük değerlerde olmaktadır. DBYBHY (2007)'de donatı çeliği şekildeğiştirme üst sınırları enine donatıdan bağımsız sabit değerler olduğundan beton donatıdan önce şekildeğiştirme üst sınır değerine ulaşmaktır. Böylece düşük dayanımlı malzeme kesitin hasarını ve eğrilik değerini beton belirlemiş olmaktadır. Benzer durum TBDY (2018)'e göre kesit hasarlarının belirlenmesinde de görülmektedir. TBDY (2018)'de beton şekildeğiştirme üst sınır değerleri kesitteki beton sınıfı ve sargılama durumu düşük olması durumunda düşük değerlerde çıkmakta, donatı çeliği şekildeğiştirme üst sınır değerleri de sargılama durumundan bağımsız sabit değerler olduğundan düşük dayanımlı malzeme kesitin hasarını ve eğrilik değerini beton belirlemiş olmaktadır.

3) Her iki yönetmelikte de; İyi dayanımlı malzeme durumunda kesit hasar sınırları birbirinden daha keskin bir şekilde ayırt edilebiliyor iken, düşük dayanımlı malzeme durumunda kesit hasar sınırları birbirine yakın değerler çıkmaktadır.

4) Düşük dayanımlı malzemeye sahip kiriş kesiti hariç diğer 13 durumun tamamında DBYBHY (2007)'e göre belirlenen Güvenlik Sınırı(GV), TBDY (2018)'deki tüm hasar sınırlardan sonra meydana gelmiştir.

5) Düşük malzemeye sahip betonarme perde kesitinde, TBDY (2018)'e göre belirlenen göçme öncesi (GÖ) hasar seviyesi eğrilik değeri DBYBHY (2007)'e göre belirlenen minimum hasar (MN) hasar seviyesine tekabül ettiği görülmektedir.

6) Her iki yönetmelikte de; Eksenel yük seviyesi artıkça aynı kesitin aynı hasar sınırına tekabül eden eğrilik değeri küçülmektedir. Dolayısı ile eksenel yük seviyesi artıkça düşey taşıyıcı elemandan hasar daha düşük şekil değiştirme değerinde oluşacağı söylenebilir. 
7) İyi ve düşük dayanımlıki malzeme gruplarının ikisinde de TBDY (2018)'ne göre belirlenen kesit hasar sınırları, DBYBHY (2007)' göre belirlenen kesit hasar sınırlarından daha küçük eğrilik değerlerinde meydana gelmektedir. Dolayısı ile TBDY (2018), deprem güvenliği açsından DBYBHY (2007)'e göre daha güvenli tarafta kalıyor denilebilir.

8) Yapılan çalışma sonucu elde edilen sonuçlar incelendiğinde, Deprem Bölgelerinde Yapılacak Yapılar Hakkında Yönetmelik ile Türkiye Bina Deprem Yönetmeliği'nin kesit hasar sınırları değerlerinde önemli miktarda farklı sonuçların olduğu gözlenmiş olup bu sonuç binanın performans seviyesini değiştirebilecek niteliktedir. Fakat iki yönetmelik arasında bina deprem güvenliğinin belirlemesi konusunda tek farklılık kesir hasar sınırları değildir. Söz konusu diğer farklılıkların da göz önüne alınması ile yapılacak yeni çalışmalar ile iki yönetmelik bina deprem güvenliği belirlemesi konusundaki daha ayrıntılı bir şekilde kıyaslanabilecektir. Bu bağlamda bu çalışma yapılacak diğer çalışmalara 1şık tutacaktır.

\section{Kaynakça}

DBYBHY. (2007). Deprem Bölgelerinde Yapılacak Binalar Hakkında Yönetmelik. Ankara: Bayındırlık ve İskan Bakanlığı.

Dilmaç, H., Ulutaş, H., Tekeli, H., ve Demir, F. (2018). An Evaluation on Seismic Performance of Existing Reinforced Concrete Buildings in Turkey. Mehmet Akif Ersoy Üniversitesi Fen Bilimleri Enstitüsü Dergisİ, 9(Ek Sayı 1): 224-237

Elci, H. ve Goker, K. A. (2018). Deprem Yönetmeliklerinin (DBYBHY 2007 ve TBDY 2018) Betonarme Kolonların Deprem Performansı Açısından Karşılaştırılması. International Journal of Scientific and Technological Research, 4(6), 9-21.

Eurocode 8 (2003). Design of Structures for Earthquake Resistance. Brussels: Comité Européen Normalisation.

Ersoy, U. ve Özcebe G. (1998). Sarılmış Betonarme Kesitlerde Moment-Eğrilik İlişkisi Analitik Bir İnceleme. Teknik Dergi, 9(4), 1998-1827.

FEMA 356 (1997). Prestandard and Commentary for Seismic Rehabilitation of Buildings. Washington: Federal Emergency Management Agency.

Iş1ltan, Ö. (2010). Yüksek Lisans Tezi. Betonarme Kolonlar için TDY 2007, EUROCODE 8 ve FEMA 356 ile Yapılan Performans Değerlendirmelerinin Deney Sonuçlarıyla Karşılaştırılması. İstanbul Teknik Üniversitesi Fen Bilimleri Enstitüsü.

Mander, J.B., Priestley, M.J.N., and Park, R.(1988). Theoretical Stress-Strain Model for Confined Concrete, Journal of Structural Division, 114(8), 1804-1826

Nemutlu, Ö. S., ve Sarı, A. (2018). International Engineering and Natural Sciences Conference. Deprem Bölgelerinde Yapılacak Binalar Hakkında Yönetmelik 2007 ile Türkiye Bina Deprem Yönetmeliği 2018'in Karşılaştırılması, (s. 568-576). Diyarbakır Türkiye.

Öztürk, T. (2005). İMO İstanbul Şubesi 2005 İlkbahar-Yaz Dönemi Meslekiçi Eğitim Kursları. Betonarme Binalarda Deprem Perdelerinin Yerleşimi ve Tasarımı

TBDY. (2018). Türkiye Bina Deprem Yönetmeliği. Ankara: Afet ve Acil Durum Yönetimi Başkanlığı.

Ulutaş, H., Tekeli, H., ve Demir, F. (2015). International Burdur Earthquake and Environment Symposium. Kesit Hasar Sınırlarının Belirlenmesinde Sargılama Durumunun Etkisi, (s. 252-259). Burdur Türkiye.

Yaman, S., Tekeli, H. \& Demir, F. (2019). Betonarme Binalarda Perde Yeri Değişiminin Bina Performansına Etkisi. Avrupa Bilim ve Teknoloji Dergisi, (16), 194-204. 